\title{
Frequency of Risk Factors and Outcome of Hospital-Acquired Acute Kidney Injury
}

Hina Iram ${ }^{1}$, Muhammad Ali ${ }^{2}$, Vinod Kumar ${ }^{3}$, Ayesha Ejaz ${ }^{1}$, Shafique A. Solangi ${ }^{1}$, Abdul Manan Junejo ${ }^{1}$ , Sagheer Ahmed Solangi ${ }^{4}$, Noor Un Nisa ${ }^{5}$

1. Department of Nephrology, Jinnah Postgraduate Medical Centre, Karachi, PAK 2. Department of Nephrology, Fazaia Ruth Pfau Medical College, Karachi, PAK 3. Department of Medicine, Sir Syed College of Medical Sciences for Girls, Karachi, PAK 4. Department of Medicine, Jinnah Postgraduate Medical Centre, Karachi, PAK 5. Physiology, Jinnah Sindh Medical University, Karachi, PAK

Corresponding author: Muhammad Ali, aliunar2002@yahoo.com

\section{Abstract}

Objective: To determine the frequencies of risk factors and the ultimate outcomes of ccute kidney injury (AKI) among hospitalized patients.

Materials and methodology: This prospective, observational study was carried out from September 15, 2018, to March 14, 2019. All admitted patients, both male and female, with AKI, were included. Those with chronic kidney disease (CKD), small size echogenic kidneys (on ultrasonography, performed on admission), and recent history of urological intervention were excluded from the study. All patients were assessed for etiological factors (sepsis, gastroenteritis, surgical, and obstetrical) and outcome (improved, progression to CKD, or expired).

Results: Out of a total of 230 , most patients were aged between 20-50 years with a mean age of $38.99 \pm 7.61$ years. Males were 144 (62.61\%) and females were 86 (37.39\%). About 78 (33.91\%) patients were hypertensive while 65 (28.26\%) were diabetic. The cause of hospital-acquired AKI was found to be sepsis in most $(71.73 \%$, $n=165)$ of the cases, followed by gastroenteritis $(10.00 \%, n=23)$, surgical $(9.56 \%, n=22)$, and obstetric $(8.69 \%$, $\mathrm{n}=20$ ) causes. When the outcome was assessed, 10 (4.35\%) patients expired, 154 (66.96\%) improved completely, while 66 (28.69\%) progressed to CKD.

Conclusion: This study has shown that sepsis is the most common cause of AKI in patients admitted to the hospital. So we recommend that proper steps should be taken to ensure adequate hospital care for avoiding such outcomes in hospitalized patients, and further decrease mortality.

Review began 11/28/2020 Review ended 12/05/2020 Published 12/09/2020

\section{() Copyright 2020}

Iram et al. This is an open access article distributed under the terms of the Creative Commons Attribution License CC-BY 4.0., which permits unrestricted use, distribution, and reproduction in any medium, provided the original author and source are credited.
Categories: Internal Medicine, Obstetrics/Gynecology, Nephrology

Keywords: sepsis, acute kidney injury, hospitalized, gastroenteritis, mortality

\section{Introduction}

Acute kidney injury (AKI), recently taking over the previous term acute-renal failure (ARF), is a sudden decline in renal function and represents both structural and functional damage. It is a fairly common condition affecting public health globally. There has been a frequent change in the definition of AKI in the past few years. Based on a consensus, the Acute Dialysis Quality Initiative (ADQI) defined ARF and established a staging criterion called the RIFLE criterion (Risk, Injury, Failure, Loss, and End-stage kidney disease) in 2002. The AKI network came into existence in 2004 and introduced the term 'Acute Kidney Injury', reflecting the entire array of ARF. According to the proposed diagnostic criteria for AKI (Kidney Disease Improving Global Outcomes - KDIGO), when there is a sudden decline (within 48 hours) in kidney function (serum creatinine $>0.3 \mathrm{mg} / \mathrm{dL}$ ), or $>50 \%$ increase in serum creatinine, or decreased urine output of $<0.5 \mathrm{~mL} / \mathrm{kg} / \mathrm{hr}$ for $>$ six hours, it is diagnosed as AKI [1-4].

There is an increasing frequency of AKI in hospitalized patients, affecting around $22 \%$ of adults, complicating the recovery from their primary disorder [5]. To reduce the incidence and further improve the outcome of AKI, immediate diagnosis, and prompt management are required. The mission of healthcare institutions is to know local epidemiology so that they can establish strategies to prevent in-hospital deaths from AKI [6]. These have already been reported in the available literature, is best known in the septic population, within the intensive (ICU), and postoperative (PCU) care units, among others [7].

AKI can lead to adverse outcomes secondary to multi-organ dysfunction including kidneys progressing to chronic kidney disease (CKD). It has an estimated mortality rate of $21 \%$ that increases with the increasing severity of AKI [8]. In a study by Evans et al., risk factors for hospital-acquired AKI were found to be sepsis (86.9\%) and gastroenteritis (GE) (19.0\%) [9]. While in a local study, Khan et al. found sepsis (16.0\%), GE (24.0\%), surgical (17.0\%), and obstetrical (5.0\%) as probable causes of AKI. Regarding outcome in these patients who improved at the end of the study, $72 \%$ of the cases were managed conservatively, $22 \%$ were 
temporarily dialyzed, $5 \%$ were advised long term dialysis as they progress to $\mathrm{CKD}$, and $13 \%$ of the cases expired [10]. Another study by the US Veterans Administration reported that increased mortality risk remains post-treatment and is increased twice at one year when compared to those without AKI [11].

Pakistan, being a developing country, does not have a well-developed health care system throughout the country. AKI is one of those disorders that can be a hurdle for managing the primary disease. Still, not much data is available on AKI as to why it develops and how it progresses. This study aimed to determine the frequencies of risk factors and the ultimate outcomes of AKI among hospitalized patients.

\section{Materials And Methods}

This prospective, observational study was carried out at the Nephrology Department, Jinnah Postgraduate Medical Centre, Karachi, Pakistan, from September 15, 2018, to March 14, 2019. The sample size was calculated by using the OpenEpi software version 3.01, which came out to be 227 with a $95 \%$ confidence level, $5 \%$ margin of error, and frequency of AKI in hospitalized patients as 18\% [8]. Legal formalities were done by taking informed consent from all patients and ethical committee approval. Non-probability, consecutive sampling technique was used.

All admitted patients, both male and female, with AKI (identified by KDIGO criteria as described above) were included. Those with CKD, small size echogenic kidneys (on ultrasonography, performed on admission), and recent history of urological intervention were excluded from the study. Those who started on renal replacement therapy (RRT) at any time of the study duration were also excluded.

All patients were assessed for etiological factors (sepsis, GE, surgical, and obstetrical) and outcome (improved or progressed to CKD, or expired). CKD was defined as patients with radiological and biochemical evidence of CKD (estimated glomerular filtration rate less than $60 \mathrm{ml} / \mathrm{min} / 1.73 \mathrm{mt}$, persisting for three months or more) but not on RRT [12]. Patients were discharged when asymptomatic (i.e. adequate urine output, normalization of creatinine, no acidosis, no hyper/hypokalemia and volume overload). They were followed-up on telephonic interviews and in the outpatient departments for up to six months.

Statistical analysis was done using Statistical Package for Social Sciences (SPSS) version 22 (IBM Corp., Armonk, NY, USA). Mean and the standard deviation was calculated for age while the gender, comorbid (hypertension, diabetes mellitus), etiological factors, and outcome were presented as frequency and percentage. The chi-square test was applied to the variables post-stratification to see their effect on the outcome. A P-value of $\leqslant 0.05$ was calculated as significant.

\section{Results}

In this study, it was established that most patients were aged between 20 to 50 years with a mean age of $38.99 \pm 7.61$ years. Out of 230 patients, males were 144 (62.61\%) and females were 86 (37.39\%) with M:F of $1.7: 1$.

When comorbidities were assessed, 78 (33.91\%) were hypertensive and 65 (28.26\%) were diabetic. The cause of hospital-acquired AKI was found to be sepsis in most $(71.73 \%, \mathrm{n}=165)$ of the cases, followed by GE (10.00\%, $n=23)$, surgical $(9.56 \%, n=22)$, and obstetric $(8.69 \%, n=20)$ causes.

Regarding the outcome in these patients, mortality was seen in 10 (4.35\%) patients, 154 (66.96\%) had improved completely, while 66 (28.69\%) progressed to CKD. Stratification according to different patient characteristics is given in Table 1 , although these associations were statistically nonsignificant. 


\section{Cureus}

\begin{tabular}{|c|c|c|c|c|c|}
\hline Variable & Total & Completely recovered $\mathrm{n}(\%)$ & Progressed to chronic $\mathbf{n}(\%)$ & Expired $n(\%)$ & p-value \\
\hline \multicolumn{6}{|l|}{ Gender } \\
\hline Male & 144 & 100 (69.44) & $36(25.00)$ & $8(5.55)$ & \multirow[t]{2}{*}{0.13} \\
\hline Female & 86 & $53(61.63)$ & $31(36.05)$ & $2(2.32)$ & \\
\hline \multicolumn{6}{|l|}{ Comorbid } \\
\hline Diabetes mellitus & 65 & $30(46.15)$ & $29(44.61)$ & $6(9.23)$ & \multirow[t]{2}{*}{0.06} \\
\hline Hypertension & 78 & $23(29.49)$ & $50(64.1)$ & $5(6.41)$ & \\
\hline \multicolumn{5}{|l|}{ Etiology } & \multirow{5}{*}{0.22} \\
\hline Sepsis & 165 & 106 (64.24) & $54(32.72)$ & $5(3.03)$ & \\
\hline Gastroenteritis & 23 & $16(69.56)$ & $5(21.74)$ & $2(8.69)$ & \\
\hline Surgical & 22 & $18(81.81)$ & $2(9.09)$ & $2(9.09)$ & \\
\hline Obstetrical & 20 & $14(70.00)$ & $5(25.00)$ & $1(5.00)$ & \\
\hline
\end{tabular}

TABLE 1: Association of patient characteristics with mortality and survival $(n=230)$

\section{Discussion}

The epidemiology of AKI in developing countries differs from that of the developed countries in many ways $[2,13-20]$. In developed countries, elderly patients predominate, while the younger population is more commonly involved in developing countries [21-22]. Compared to the other part of the world, finding the actual incidence of AKI is very difficult when we search for the data in developing countries. Seedat et al. reported an incidence of 20 cases per million populations per year in South Africa [23]. While in North India, Jha et al. reported an incidence of 6.4/1000 admissions per year [24]. AKI is associated with tremendous consumption of health-care resources, morbidity, and mortality especially in patients admitted to the hospital. The occurrence of kidney failure in patients admitted to hospital for non-renal problems complicates the hospital course with an out-and-out impact on patient outcomes. An increased incidence of sepsis and a lack of well-trained personals to deal with intensive care, hamper the efforts to prevent AKI. The costs of RRT are also prohibitively high in developing countries [25-26]. Sepsis was the dominant cause of AKI in our study (64.24\%), with a mortality of 3.03\%.

In a prospective study, the incidence of AKI was eight per 1000 admissions, of which $7.8 \%$ was hospitalacquired AKI. As far as the etiology is concerned, $87.4 \%$ had medical diagnoses (sepsis being the most common at $53.1 \%$ ), $9.4 \%$ had surgical, while $3.2 \%$ had obstetric problems. Among sepsis, urosepsis and pneumonia were the most common causes. Nearly $38.2 \%$ had a multi-organ failure, $23.3 \%$ required dialysis, while mortality was $8.7 \%$. Predictive factors of mortality included anemia, the need for intensive care, and the use of vasopressin drugs. Many of these are potentially preventable with early and proper fluid replacement, appropriate antidotes, effective anti-infective treatment, early referral to nephrologists, and specialized dialysis units [16].

In another prospective observational study, a total of 412 patients ( $52.6 \%$ males and $47.4 \%$ females, including 7.5\% human immunodeficiency virus [HIV] infected patients) were included, out of which $10.9 \%$ had AKI. Hypoperfusion and sepsis, mainly because of infection with the malarial parasite (42.2\%), were the commonest causes of AKI. In-hospital mortality was $20.5 \%$ and $2.9 \%$ with and without AKI, respectively. Around $47.2 \%$ with renal disease had persistent kidney injury at the time of discharge from the hospital.

The incidence of AKI in hospitalized adults in Africa was found to be $0.3-1.9 \%$, where $90 \%$ were not nosocomial. Most of the patients with AKI had a mean age of 41.3 \pm 9.3 years and an M:F ratio of 1.2:1. Iatrogenic causes accounted for $65-80 \%$ of cases of AKI, followed by obstetric (5-27\%), and surgical (2-24\%) causes. In the reported studies, $17-94 \%$ of patients needed dialysis while the mortality rate was $11.5-43.5 \%$ [27].

Hsu et al. in their retrospective work examined 734,340 in Taiwan, where AKI was detected in 1.68-2\% of the hospital discharges among adults with and without preexisting CKD respectively. The incidence of hospital-acquired AKI was 814 per 100,000 admissions. In-hospital mortality (26.07\% vs $51.58 \%$ ) was found to be higher with more severe outcomes in patients who had acquired AKI in the hospital unlike that of community-acquired AKI [28]. 
In a study on 220 patients, where $86.81 \%$ survived, GE was the commonest etiology of AKI in $27.3 \%$ of participants reflecting the high incidence of disease in the community, followed by sepsis in $14.1 \%$ and pyelonephritis in $12.3 \%$. Among these, sepsis had the highest mortality ( $\mathrm{n}=11,35.5 \%)$, and GE and acute febrile illness had the least mortality $(1.7 \%$ and $0 \%)$, respectively $(\mathrm{P}<0.005)[29]$.

Similarly, this study had a higher proportion of males (62.61\%) with M:F of 1.7:1. AKI had sepsis as the most common etiology $(71.73 \%, \mathrm{n}=165)$, followed by GE $(10.00 \%, \mathrm{n}=23)$. Regarding the outcome in these patients, mortality was seen in 10 (4.35\%) patients, with $8.69 \%$ deaths in patients GE and $9.09 \%$ in those of surgical causes.

Our study is limited by the fact that mortality was not assessed after hospital discharge and the duration of hospital and especially ICU stay was not determined. Follow-up was just for six months with no assessment of outcomes later. Data was just from a single dialysis center of a public sector hospital. Lastly, a larger sample collection would have given more statistically significant results.

\section{Conclusions}

This study has shown that sepsis is the most common cause of AKI in patients admitted to the hospital. We recommend that proper steps should be taken to ensure adequate hospital care for avoiding such outcomes in hospitalized patients and further decrease mortality.

\section{Additional Information \\ Disclosures}

Human subjects: Consent was obtained by all participants in this study. Jinnah Postgraduate Medical Center issued approval N0.F.2-81-IRB/2017/4782/JPMC. Reference to your letter dated 30th October 2017, on the subject noted above and to say that the institutional review board has approved your proposal. Animal subjects: All authors have confirmed that this study did not involve animal subjects or tissue. Conflicts of interest: In compliance with the ICMJE uniform disclosure form, all authors declare the following: Payment/services info: All authors have declared that no financial support was received from any organization for the submitted work. Financial relationships: All authors have declared that they have no financial relationships at present or within the previous three years with any organizations that might have an interest in the submitted work. Other relationships: All authors have declared that there are no other relationships or activities that could appear to have influenced the submitted work.

\section{References}

1. Singh TB, Rathore SS, Choudhury TA, Shukla VK, Singh DK, Prakash J: Hospital-acquired acute kidney injury in medical, surgical, and intensive care unit: A comparative study. Indian J Nephrol. 2013, 23:24-9. 10.4103/0971-4065.107192

2. Jha V, Malhotra HS, Sakhuja V, Chugh KS: Spectrum of hospital-acquired acute renal failure in the developing countries--Chandigarh study. Q J Med. 1992, 83:497-505.

3. KDIGO Clinical Practice Guideline for Acute Kidney Injury. (2012). https://kdigo.org/wpcontent/uploads/2016/10/KDIGO-2012-AKI-Guideline-English.pdf.

4. Classification Systems for Acute Kidney Injury . (2018). https://emedicine.medscape.com/article/1925597overview.

5. Wang HE, Powell TC, Gutierrez OM, Griffin R, Safford MM: Prehospitalization risk factors for acute kidney injury during hospitalization for serious infections in the REGARDS cohort. Nephron Extra. 2015, 5:87-99. $10.1159 / 000441505$

6. Murray PT, Mehta RL, Shaw A, Ronco C, Endre Z, Kellum JA: Potential use of biomarkers in acute kidney injury: report and summary of recommendations from the 10th Acute Dialysis Quality Initiative consensus conference. Kidney Int. 2014, 85:513-21. 10.1038/ki.2013.374

7. Finlay S, Bray B, Lewington AJ, Hunter-Rowe CT, Banerjee A, Atkinson JM: Identification of risk factors associated with acute kidney injury in patients admitted to acute medical units. Clin Med. 2013, 13:233-8. 10.7861/clinmedicine.13-3-233

8. Mehta RL, Burdmann EA, Cerda J, Feehally J, Finkelstein F, Garcia-Garcia G: Recognition and management of acute kidney injury in the International Society of Nephrology 0by25 Global Snapshot: a multinational cross-sectional study. Lancet. 2016, 387:2017-25. 10.1016/S0140-6736(16)30240-9

9. Evans RDR, Hemmila U, Craik A, Mtekateka M, Hamilton F, Kawale Z: Incidence, aetiology and outcome of community-acquired acute kidney injury in medical admissions in Malawi. BMC Nephrol. 2017, 18:21. 10.1186/s12882-017-0446-4

10. Khan RN, Vohra EA, Suleman W: Factors determining outcome of acute renal failure patients . J Pak Med Assoc. 2005, 55:526-30.

11. Lafrance J-P, Miller DR: Acute kidney injury associates with increased long-term mortality . J Am Soc Nephrol. 2010, 21:345-52. 10.1681/ASN.2009060636

12. Vaidya S, Aeddula N: Chronic Renal Failure. StatPearls, Treasure Island; 2020.

13. Cerda J, Bagga A, Kher V, Chakravarthi RM: The contrasting characteristics of acute kidney injury in developed and developing countries. Nat Clin Pract Nephrol. 2008, 4:138-53. 10.1038/ncpneph0722

14. Waikar SS, Liu KD, Chertow GM: Diagnosis, epidemiology and outcomes of acute kidney injury . Clin J Am Soc Nephrol. 2008, 3:844-61. 10.2215/CJN.05191107

15. Noronha IL, Schor N, Coelho SN, Jorgetti V, Romao Junior JE, Zatz R: Nephrology, dialysis and 
transplantation in Brazil. Nephrol Dial Transplant. 1997, 12:2234-43. 10.1093/ndt/12.11.2234

16. Thomas CN, Brann SH, Douglas AR, Thomas JM, Daniel SC, Posthoff C: Coronary artery bypass graft outcome: the Trinidad and Tobago experience. West Indian Med J. 2000, 49:290-3.

17. Al-Homrany M: Epidemiology of acute renal failure in hospitalized patients: experience from southern Saudi Arabia. East Mediterr Health J. 2003, 9:1061-7.

18. Vukusich A, Alvear F, Villanueva P, Gonzalez C, Francisco O, Alvarado N: Epidemiology of severe acute renal failure in Metropolitan Santiago. Rev Med Chil. 2004, 132:1355-61. 10.2215/CJN.04961107

19. Kohli HS, Bhat A, Jairam A, Aravindan AN, Sud K, Jha V: Predictors of mortality in acute renal failure in a developing country: a prospective study. Ren Fail. 2007, 29:463-9. 10.1080/08860220701260651

20. Wang Y, Cui Z, Fan M: Hospital-acquired and community-acquired acute renal failure in hospitalized Chinese: a ten-year review. Ren Fail. 2007, 29:163-8. 10.1080/08860220601095918

21. Arije A, Kadiri S, Akinkugbe OO: The viability of hemodialysis as a treatment option for renal failure in a developing economy. Afr J Med Med Sci. 2000, 29:311-4.

22. Waikar SS, Curhan GC, Wald R, McCarthy EP, Chertow GM: Declining mortality in patients with acute renal failure, 1988 to 2002. J Am Soc Nephrol. 2006, 17:1143-50. 10.1681/ASN.2005091017

23. Seedat YK, Nathoo BC: Acute renal failure in blacks and Indians in South Africa--comparison after 10 years . Nephron. 1993, 64:198-201. 10.1159/000187314

24. Jha V, Chugh KS: Acute renal failure in the tropics . J Assoc Physicians India. 1997, Suppl 2:18-23.

25. Moosa MR, Kidd M: The dangers of rationing dialysis treatment: the dilemma facing a developing country . Kidney Int. 2006, 70:1107-14. 10.1038/sj.ki.5001750

26. Dirks JH, Levin NW: Dialysis rationing in South Africa: a global message . Kidney Int. 2006, 70:982-4. 10.1038/sj.ki.5001798

27. Adu D, Okyere P, Boima V, Matekole M, Osafo C: Community-acquired acute kidney injury in adults in Africa. Clin Nephrol. 2016, 86:48-52. 10.5414/CNP86S121

28. Hsu C-N, Lee C-T, Su C-H, Wang Y-CL, Chen H-L, Chuang J-H: Incidence, outcomes, and risk factors of community-acquired and hospital-acquired acute kidney injury: A retrospective cohort study. Medicine. 2016, 95:e3674. 10.1097/MD.0000000000003674

29. Anvar M, Raghavendra B: Etiological variability affecting the clinical outcomes of patients admitted with acute kidney injury in a tertiary care hospital. J Integr Nephrol Androl. 2018, 5:60-5. 10.4103/jina.jina_7_18 